\title{
Validation of an Ultrashort Persian Version of Oral Health Impact Profile (OHIP-5) Questionnaire
}

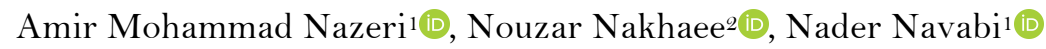

${ }^{1}$ Department of Oral Medicine, Kerman Dental School, Kerman University of Medical Sciences, Kerman, Iran.

${ }^{2}$ Neuroscience Research Center, Institute of Neuropharmacology, Kerman University of Medical Sciences, Kerman, Iran.

Author to whom correspondence should be addressed: Nader Navabi, Department of Oral Medicine, Kerman Dental School, Kerman University of Medical Sciences, Medical University Campus, Haft-Bagh Highway, Kerman, Iran. 7616913555. Phone: 0983432118071 . E-mail:nader_nawabi@yahoo.com.

Academic Editors: Alessandro Leite Cavalcanti and Wilton Wilney Nascimento Padilha

Received: 14 June 2019 / Accepted: 20 September 2019 / Published: 25 October 2019

How to cite this article: Nazeri AM, Nakhaee N, Navabi N. Validation of an ultrashort Persian version of Oral Health
Impact Profile (OHIP-5) Questionnaire. Pesqui Bras Odontopediatria Clín Integr. 2020; $20: e 5073$.
https://doi.org/10.1590/pboci.2020.001

\begin{abstract}
Objective: To validate the ultrashort (5-item) Persian version of OHIP by investigating its psychometric properties. Material and Methods: Construct validity was assessed by examining the correlation between OHIP-5 scores and self-reported oral health status, judgment for dental treatment needs and the number of natural teeth. Reliability was calculated using Cronbach's alpha and corrected item-total correlation. Effect size (ES) and Standardized Response Mean (SRM) were calculated for the responsiveness of the scale and factor analysis was done by measuring Kaiser-Meyer-Olkin (KMO), Bartlett's sphericity test and scree plot. Results: In 430 subjects (mean age $41.56+/-11.35$ years, $56 \%$ female) the correlations between OHIP-5 scores and mentioned items were significant $(\mathrm{p}<0.01)$ indicating sufficient construct validity. The reliability coefficient (Cronbach's alpha) of the OHIP-5 was above the recommended 0.7 thresholds (0.809) and considered well. For evaluation of responsiveness, the ES was measured to be 5.604 and the SRM was 1.5. Moreover, in the confirmatory factor analysis, the unidimensional model for OHIP 5 approved by indices $(\mathrm{KMO}=0.81, \mathrm{p}<0.001$ for Bartlett sphericity). Conclusion: The Persian version of OHIP-5 is a precise, valid, reliable and unidimensional instrument for assessing oral health-related quality of life among the general adult population.
\end{abstract}

Keywords: Oral Health; Quality of Life; Surveys and Questionnaires; Reproducibility of Results. 


\section{Introduction}

Oral health-related quality of life (OHQoL) is a criterion which is known worldwide in dental research, therapeutic and educational fields and its definition has been based on the absence of negative impacts of oral conditions on social life and a positive sense of oral and dental self-confidence [1].

To date, OHIP (Oral Health Impact Profile) questionnaire has been the most commonly used tool for the evaluation of OHQoL all over the world. It was first designed in 1884, consisted of 49 questions (OHIP-49) [2]. Later, since the questionnaire consisted of many items, researchers designed a more concise version of the questionnaire with 14 questions (OHIP-14), which became very popular for the evaluation of OHQoL in different populations and for determining the effect of various dental interventions on OHQoL [3-5].

In addition, it was translated into different languages since researchers greatly need to use it in different research plans [1,5]. Finally, the most concise form of the OHIP tool was designed with 5 questions because more concise tools are necessary for the evaluation of oral health at national levels with very large sample sizes, so that more concise conclusions can be drawn from a large mass of collected data. This version of OHIP was called the ultra-short version of the questionnaire [6].

Since the number of questions in the OHIP-5 tool is $10 \%$ of that in the original questionnaire (OHIP49 ), it contains $98 \%$ of other input data in its items, making it an interesting tool for effectively determining OHQoL [6,7]. However, questionnaires such as questionnaires used to assess the quality of life, whose questions deal with cultural and psychological concepts, require validation studies after they are translated into another language so that the responses elicited by the questionnaire can be relied on in that language [8].

The original German questionnaire has to date been translated and validated into five languages English [7], Japanese [9], Dutch [6,10], Swedish [11] and Chilean [12]. Iran, Tajikistan and Afghanistan are three countries in which Persian is an official language. Over 65.000.000 million people in Iran, 19.000.000 million in Afghanistan and 7.000.000 million in Tajikistan, speak Persian and making Persian the largest language by the number of speakers in these countries, causing validation of Persian version of such questionnaire important.

The present study aimed to confirm psychometric properties (including validity, reliability, responsiveness and factor analysis) of the Persian version of OHIP-5.

\section{Material and Methods}

\section{Study Design}

The present validation study was conducted in Kerman, the capital of the largest province of Iran. The subjects were randomly selected from the participants of dental school, and dental clinics consisted of patients and those accompanying them for convenience. The subjects were 18-65 years of age. A senior trained dental student used an interviewer-administered questionnaire to collect the data. Four hundred subjects were included based on the largest sample size, which is routine for such studies [13].

\section{Data Collection}

The OHIP-5 questionnaire, consisting of 5 questions, was completed for all the subjects; questions on this tool were the selected questions for similar studies in the German and English languages and its Persian text was the validated version in Persian $[6,7,14]$. The questions asked the subjects "to explain the oral and dental problems based on their experience during the previous 12-month period.” The responses were scored from zero to 4 for (never, hardly ever, occasionally, fairly often and very often) respectively, with a total score 
range of $0-20$ for 5 questions. Higher scores indicated the poorer oral health-related quality of life. In addition, the demographic data of all the subjects (including age, gender and educational level) were recorded.

To determine construct validity, first the following variables were recorded for each subject: the subjects' self-reported oral health status, the subjects' self-judgment about their need for dental treatment(s), an oral examination in terms of the number of natural permanent teeth present in the oral cavity ( $>20$ and $<20$ ). It was expected that the mean total scores of the completed questionnaire would be different in terms of the variables above.

\section{Data Analysis}

To assess validity, an independent t-test was used to compare the means. Statistical significance was defined at 0.01 at a confidence interval (CI) of 95\%. The reliability (internal consistency) of the questionnaire was assessed by determining Cronbach's alpha for all the 5 items and for each item. The minimum acceptable value for Cronbach's alpha at 95\% CI was set at 0.7. The following coefficients, too, were calculated to confirm the correlation between the data on reliability: scale mean and variance if item deleted, corrected item-total correlation and Cronbach's alpha if item deleted. The tool's responsiveness was determined through the calculation of the two parameters of effect size (ES) and standardized response mean (SRM). In this context, the questionnaire was completed twice, once before the intervention and once one month after intervention for 30 patients who presented with a toothache and their teeth were extracted through surgical intervention. It was expected that an acceptable difference would be observed between these two stages in the responses provided for the questionnaire, with $\mathrm{SRM}>0.8$, indicating a large effect resulting from the intervention [15].

Factor analysis was carried out to determine the number of factors extracted from one questionnaire and confirm its factorable nature, i.e., to make sure that it is possible, to sum up the results of the response to the questionnaire questions and report a total score. To carry out factor analysis, KMO (Kaiser-Myer-Olkin) and MSA (measure of sampling adequacy) were calculated; a scree plot was drawn and total variance was calculated [16].

Ethical Aspects

The protocol of this study was approved by the Ethics Committee of Kerman University of Medical Sciences under the code IR.KMU.REC.1396.1900. The subjects' demographic data were kept confidential and they answered the questions on the questionnaire if they were willing to.

\section{Results}

A total of 430 subjects were included in the present study, with a mean age of $41.56 \pm 11.35$ years. Concerning to educational level, $41.2 \%$ of the subjects were university graduates, $32 \%$ were high school graduates, $23.3 \%$ had some school education and $3.5 \%$ were illiterate.

Table 1 presents the results of the validation of the OHIP-5 questionnaire for the subjects. As shown in the table, the mean scores on the questionnaire in all the three criteria (i.e., self-reported oral health, selfjudgment about the need for dental treatments and the number of natural teeth remaining in the subjects' oral cavities) were significantly different $(\mathrm{p}<0.01)$.

Table 2 presents the frequency distributions of the subjects' responses to 5 questions on the questionnaire. The total mean score of the subjects was $7.986 \pm 3.915$, with a range of $0-18$. 
Table 1. Construct validity assessment for OHIP-5 in Persian.

\begin{tabular}{llcc}
\hline \multicolumn{1}{c}{ Variables } & Category & N (\%) & Item-Score Correlation \\
\hline Self-Reported Oral Health & Poor & $148(34.4)$ & $<000.1^{*}$ \\
& Moderate & $207(48.1)$ & \\
Perceived Need to Dental Treatments & Good & $75(17.4)$ & \\
& Yes & $375(87.2)$ & $0.021^{*}$ \\
& No & $16(3.7)$ & $<000.1^{*}$ \\
Number of Natural Teeth & I do not Know & $39(9.1)$ & \\
\hline
\end{tabular}

*Statistically Significant: $\mathrm{p}<0.05$.

Table 2. Frequency distribution of reported impacts on the five items of the questionnaire.

\begin{tabular}{lccccc}
\hline \multicolumn{1}{c}{ Items } & \multicolumn{3}{c}{ Frequency } \\
& Never & Rarely & Usually & Often & $\begin{array}{c}\text { Always } \\
\mathrm{N}(\%)\end{array}$ \\
& $\mathrm{N}(\%)$ & $\mathrm{N}(\%)$ & $\mathrm{N}(\%)$ & $\mathrm{N}(\%)$ \\
\hline Had difficulty chewing any foods & $168(39.1)$ & $155(36.1)$ & $91(21.1)$ & $15(3.5)$ & $1(0.2)$ \\
Had painful aching in mouth & $97(22.5)$ & $178(41.4)$ & $133(30.1)$ & $22(5.0)$ & - \\
Felt that there has been less flavor in food & $114(26.5)$ & $181(42.0)$ & $106(24.6)$ & $29(6.9)$ & - \\
Felt uncomfortable about the appearance & $108(25.1)$ & $154(35.8)$ & $112(26.1)$ & $56(13.0)$ & - \\
Had difficulty doing your usual jobs & $104(24.2)$ & $108(25.1)$ & $144(33.5)$ & $61(14.2)$ & $13(3.0)$ \\
\hline
\end{tabular}

Table 3 presents the coefficients related to the reliability of the questionnaire. As shown in the table, all the Cronbach's alpha coefficients were $>0.7$ with consecutive removal of the questions on the 5 -question questionnaire. Evaluation of the reliability of the questionnaire yielded a Cronbach's alpha coefficient of 0.809; therefore, the internal consistency of the questionnaire was confirmed.

Table 3. Reliability assessment for OHIP-5 in Persian.

\begin{tabular}{|c|c|c|c|}
\hline Item-scale Correlation & $\begin{array}{c}\text { Mean Score if Item } \\
\text { Deleted }\end{array}$ & $\begin{array}{l}\text { Cronbach's alpha if } \\
\text { Item Deleted }\end{array}$ & Item-scale Correlation \\
\hline $0.39^{* * *}$ & $7.083^{*}$ & $0.825^{* * * *}$ & $0.39 * *$ \\
\hline 0.649 & 6.055 & 0.756 & 0.649 \\
\hline 0.699 & 6.218 & 0.739 & 0.699 \\
\hline 0.596 & 6.067 & 0.774 & 0.596 \\
\hline 0.655 & 6.518 & 0.752 & 0.655 \\
\hline
\end{tabular}

*Between 0-20; *** $>0.3$ Acceptable; **** $>=0.7$ Acceptable.

Evaluation of the responsiveness of the tool and re-evaluation of a 30-subject group showed a 1-score decrease in the total score, indicating improvement in the quality of life. In addition, the calculated coefficients related to the responsiveness of the tool $(\mathrm{ES}=5.604, \mathrm{SRM}=1.5)$ showed a large effect subsequent to the intervention.

The results of the exploratory factor analysis showed that MSA was at an acceptable level (0.81), and the one-factor solution was extracted based on the Scree criterion. The determinant score was higher than the minimum acceptable level of 0.00001 (0.190), indicating no multi-collinearity. The total variance explained was higher than the minimum acceptable level of 0.32 (Table 4). Therefore, the overall results confirmed the factorial validity of the questionnaire. The KMO coefficient, too, was significant for the adequacy of Bartlett's test for sphericity $\left(\alpha_{2}=708.9, \mathrm{p}<0.001, \mathrm{df}=10\right)$. All the coefficients for the efficacy of sampling were $>0.7$. The results of the scree plot indicated one-factor nature with a variance of $57.1 \%$ (Figure 1 ). 
Table 4. Factor analysis.

\begin{tabular}{cc}
\hline Unidimensional & Number of Question \\
\hline 0.428 & 1 \\
0.741 & 2 \\
0.811 & 3 \\
0.665 & 4 \\
0.739 & 5 \\
\hline
\end{tabular}

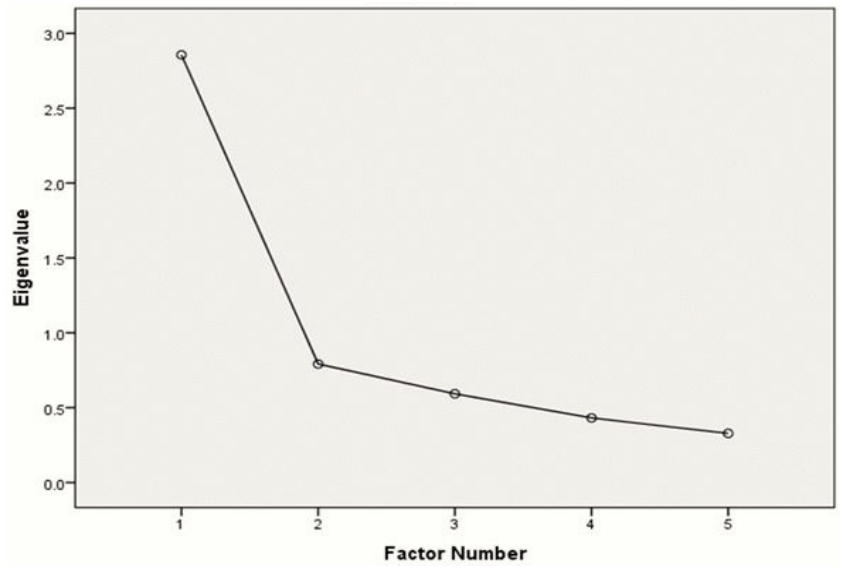

Figure 1. Scree plot of eigenvalues of factors to determine the number of factors in factor analysis of OHIP-5.

\section{Discussion}

The results of the present study showed favorable psychometric characteristics for the Persian version of the OHIP-5 questionnaire. The sample size in similar studies has varied from 85 to 1309 subjects $[6,7,9,12]$, and the sample size in the present study was only smaller than that in a Swedish study [11] and very similar to that in a British study [7]. It is evident that the accuracy of such studies increases with an increase in the sample size. In one study the researchers considered a sample size of 2050 for their research; because they tried to develop a questionnaire and in this context; developing a scale requires a larger sample size than validation [6].

The mean age of the subjects in the present study was 41.5 years. In all the three similar studies in Germany [6], England [7] and the Netherland [10], the mean age of the subjects was 40-49 years. The mean age in the Chilean study was 69.02 years; in that study, the aim was to evaluate the questionnaire in elderly subjects [12] specifically. In all previous studies, the majority of the subjects were female (52-64.1\%), similar to the present study; it might be attributed to the fact that females refer to dental clinics more frequently than males $[6,7,9,12]$.

The validity of the questionnaire was evaluated using the three criteria of "self-reported oral health", "self-judgment of the need for dental treatments" and "the number of natural teeth remaining in the oral cavity”. Four studies in Germany [6], England [7], Japan [9], and Sweden [11] the self-reported oral health criterion have been used to this end, similar to the present study. However, in Japanese study "self-reported denture quality"; in Dutch study "the relationship between temporo-mandibular joint disorders and psychological complications (Axis 2)"; and in Chilean study "dental caries", "the need for complex periodontal treatments" and "the need for prosthetic treatments" have been used instead [9,10,12]. It appears the diversity of the clinical criteria that can be used for the evaluation of validity has resulted in a low rate of similarity between studies. 
A comparison of the reliability coefficients in the present study with those of previous studies showed that Cronbach's alpha coefficient was 0.809 in the present study, which was in the range of this coefficient (0.75-0.93) in those studies [7,9,12]. The total Cronbach's alpha coefficient in the present study was higher than that in British [7] and Swedish [11] studies and lower than that in the Chilean study [12]; however, its difference from that in Japanese study (0.81) was minor [9]. The reported reliability coefficients in Dutch research was not sufficient and in the moderate to good range. However, these researchers used the test-re-test method for the evaluation of reliability and it appears Cronbach's alpha coefficient for validation studies is more effective than the test-re-test method [10,13].

In German [6] and Japanese [9] studies, similar to the present study, researchers have tried to determine the responsiveness in their studies. The effect size in the present study (0.604) was larger than that in Japanese study (6.57) [9] and within the range of this coefficient in German study (0.55-0.98) [6]. In Japanese [9] and German [6] studies, investigators considered "partial prosthetic treatment" and "pain resulting from temporo-mandibular joint disorders" as a clinical intervention, respectively, which are different from the therapeutic intervention used in the present study. However, as it can be inferred from the relevant coefficients, the current translated version of the questionnaire revealed the changes in the subjects' quality of life much better compared to the studies above.

In previous studies, only in the British version [7], similar to the present study, factor analysis has been carried out, and in that study, similar to the present study, the unidimensional nature of the OHIP-5 questionnaire was confirmed. In this unidimensional model, all five items are correlated and load on a common factor representing OHQoL [17,18]. However, the coefficients used in British study [7] to this end were different from those in the present study. In the British study, investigators reported the following coefficients: comparative fit index; SRMR (standardized root mean square residual) and RMSEA (root mean square error of approximation) [7]. Firstly, for factor analysis of OHIP-49, German investigators described their aggregate data consisted of responses of subjects from six different countries however the findings of the recent study suggested that the OHIP-14 is also one dimensional, thereafter the researchers emphasized that additional investigations are needed towards a better understanding of the dimensionality of the OHIP-14 [19,20].

\section{Conclusion}

The present study revealed that an ultrashort unidimensional instrument met the standard criteria for validity, reliability and responsiveness. Hence, the Persian version of the OHIP-5 scale could be considered as a scientifically sound instrument, making this instrument suitable for the future OHQoL studies in Iran. Moreover, for the first time validation of OHIP-5 has been done with the assessment of both "responsiveness" and "factor analysis" in the present study and with these full psychometric assessments, it seems that our study could be considered as a perfect model for future studies in this field.

\section{Authors' Contributions}

AMN (D) 0000-0002-4605-4755 Conceptualization, Supervision, Formal Analysis, Investigation, Writing - Original Draft Preparation and Writing - Review and Editing.

NN (D) 0000-0001-5808-6503 Formal Analysis, Investigation and Writing - Review and Editing.

NN (D) 0000-0001-6321-0089 Formal Analysis, Writing - Original Draft Preparation and Writing - Review and Editing.

All authors declare that they contributed to critical review of intellectual content and approval of the final version to be published. 


\section{Financial Support}

Social Determinants on Oral Health Research Center, Kerman University of Medical Sciences (Grant No: 96.696).

\section{Conflict of Interest}

The authors declare no conflicts of interest.

\section{References}

[1] Bennadi D, Reddy CV. Oral health related quality of life. J Int Soc Prev Community Dent 2013; 3(1):1-6. https://doi.org/10.4103/2231-0762.115700

[2] Slade GD, Spencer AJ. Development and evaluation of the Oral Health Impact Profile. Community Dent Health 1994; 11(1):3-11.

[3] Slade GD. Derivation and validation of a short-form oral health impact profile. Community Dent Oral Epidemiol 1997; 25(4):284-90. https://doi.org/10.1111/j.1600-0528.1997.tbo0941.x

[4] Slade GD. Oral health-related quality of life is important for patients, but what about populations? Community Dent Oral Epidemiol 2012; 40(Suppl 2):39-43. https://doi.org/10.1111/j.1600-0528.2012.00718.x

[5] Sischo L, Broder HL. Oral health-related quality of life: what, why, how, and future implications. J Dent Res 2011; 90(11):1264-70. https://doi.org/10.1177/0022034511399918

[6] John MT, Miglioretti DL, LeResche L, Koepsell TD, Hujoel P, Micheelis W. German short forms of the Oral Health Impact Profile. Community Dent Oral Epidemiol 2006; 34(4):277-88.

https://doi.org/10.1111/j.1600-0528.2006.00279.x

[7] Naik A, John MT, Kohli N, Self K, Flynn P. Validation of the English-language version of 5-item Oral Health Impact Profile. J Prosthodont Res 2016; 60(2):85-91. https://doi.org/10.1016/j.jpor.2015.12.003

[8] Locker D, Jokovic A, Clarke M. Assessing the responsiveness of measures of oral health-related quality of life. Community Dent Oral Epidemiol 2004; 32(1):10-8. https://doi.org/10.1111/j.1600-0528.2004. 00114.x

[9] Baba K, Inukai M, John MT. Feasibility of oral health-related quality of life assessment in prosthodontic patients using abbreviated Oral Health Impact Profile questionnaires. J Oral Rehabil 2008; 35(3):224-8. https://doi.org/10.1111/j.1365-2842.2007.01761.x

[10] Van der Meulen MJ, John MT, Naeije M, Lobbezoo F. Developing abbreviated OHIP versions for use with TMD patients. J Oral Rehabil 2012; 39(1):18-27. https://doi.org/10.1111/j.1365-2842.2011.02242.x

[11] Larsson P, John M, Hakeberg M, Nilner K, List T. General population norms of the Swedish short forms of Oral Health Impact Profile. J Oral Rehabil 2014; 41(4):275-81. https://doi.org/10.1111/joor.12137

[12] León S, Correa-Beltrán G, De Marchi RJ, Giacaman RA. Ultra-short version of the oral health impact profile in elderly Chileans. Geriatr Gerontol Int 2017; 17(2):277-85. https://doi.org/10.1111/ggi.12710

[13] Charter RA. Sample size requirements for precise estimates of reliability, generalizability, and validity coefficients. J Clin Exp Neuropsychol 1999; 21(4):559-66. https://doi.org/10.1076/jcen.2 1.4.559.889

[14] Navabi N, Nakhaee N, Mirzadeh A. Validation of a Persian version of the Oral Health Impact Profile (OHIP-14). Iranian J Publ Health 2010; 39(4):135-9.

[15] John MT, Rener-Sitar K, Baba K, Čelebić A, Larsson P, Szabo G, et al. Patterns of impaired oral health-related quality of life dimensions. J Oral Rehabil 2016; 43(7):519-27. https://doi.org/10.1111/joor.12396

[16] Mignani S, Rodrigues J, Roy R, Shi X, Ceña V, El Kazzouli S, et al. Exploration of biomedical dendrimer space based on in-vitro physicochemical parameters: key factor analysis (Part 1). Drug Discov Today 2019; 24(5):1176-83. https://doi.org/10.1016/j.drudis.2019.02.014

[17] John MT, Reissmann DR, Feuerstahler L, Waller N, Baba K, Larsson P, et al. Exploratory factor analysis of the Oral Health Impact Profile. J Oral Rehabil 2014; 41(9):635-43. https://doi.org/10.1111/joor.12192

[18] John MT, Feuerstahler L, Waller N, Baba K, Larsson P, Celebić A, et al. Confirmatory factor analysis of the Oral Health Impact Profile. J Oral Rehabil 2014; 41(9):644-52. https://doi.org/10.1111/joor.12191

[19] John MT, Reissmann DR, Feuerstahler L, Waller N, Baba K, Larsson P, et al. Factor analyses of the Oral Health Impact Profile - Overview and studied population. J Prosthodont Res 2014; 58(1):26-34. https://doi.org/10.1016/j.jpor.2013.11.002

[20] Santos CM, Oliveira BH, Nadanovsky P, Hilgert JB, Celeste RK, Hugo FN. The Oral Health Impact Profile-14: a unidimensional scale? Cad Saúde Pública 2013; 29(4):749-57. https://doi.org/10.1590/so 102-311 x2013000800012 